\title{
Lack of semantic activation from unattended text during passage reading
}

\author{
ALBRECHT WERNER INHOFF and RICHARD TOPOLSKI \\ State University of New York, Binghamton
}

\begin{abstract}
Two-line passages were read while eye movements were measured. The first line contained a primary target; directly below the primary target, the second line contained the secondary target. The semantic relatedness of primary and secondary targets was varied. The results showed no reliable effects of semantic relatedness when viewing time on the primary target was examined but some effects of relatedness when viewing time on the secondary target was examined. The results suggest that readers do not obtain semantic information from unattended lines of text during reading.
\end{abstract}

A substantial number of studies have examined the representation of attended and unattended text (for reviews, see Cowan, 1988; Holender, 1986). Recently, Inhoff and Briihl (1991) used the selective reading task, which is akin to the dichotic listening task, to examine the representation of unattended text during skilled reading. In selective reading, the subject reads one line of text (attended text) but has to ignore text on the line immediately below it (unattended text). Replicating earlier results (Willows \& MacKinnon, 1973), Inhoff and Briihl's forced-choice results showed that readers obtained semantic information from unattended lines. However, detailed examinations of eye-movement records also revealed that readers occasionally fixated to-be-ignored lines of text. When these instances were eliminated, the text from unattended lines no longer biased forced-choice performance. Since shifts in eye position have been linked to shifts in visuospatial attention (e.g., McConkie, 1979; Morrison, 1984), Inhoff and Briihl's results suggest that shifts of visuospatial attention precede the acquisition of useful semantic information during reading.

However, it could be argued that text on unattended and nonfixated lines activated semantic representations in Inhoff and Briihl's (1991) study. Activation may have been of relatively short duration and was thus not tapped by the delayed memory measure, that is, Inhoff and Briihl's forced-choice task. Furthermore, the selective reading paradigm may trigger a reader's interest in the to-beignored line of text. Marcel's (1983) work indicated that an "active" search set tends to inhibit the acquisition of semantic information from (sub)threshold stimuli. Likewise, readers in the selective reading task may become active seekers of semantic information from to-beneglected text, which may interfere with the acquisition of semantic information prior to attention engagement.

\footnotetext{
This work was supported by NSF Grant BNS9017880. Correspondence should be addressed to A. W. Inhoff, Department of Psychology, SUNY-Binghamton, Binghamton, NY 13902-6000.
}

To examine these possibilities, this study instructed subjects to read two-line passages of text. The top line contained a primary target word; the lower line contained a secondary target word immediately below it. The relatedness of primary and secondary targets was varied. Primary and secondary targets were either identical, semantically related, or unrelated. Since both lines of text were read, there was little motivation to engage in an active lower-line processing mode while the top line was being read. Fixation time on the primary target was measured, providing an on-line measure of semantic activation of unattended text. If readers obtained semantic information from the secondary (unattended) target while fixating the primary (attended) target, then their semantic relationship should affect the viewing time of primary targets.

Two measures of primary and secondary target viewing time were obtained: first-fixation durations, which consisted of the duration of the first fixation on primary and secondary target words, and gaze durations, which consisted of the cumulated viewing time on primary and secondary targets prior to the fixation of the next word in the text.

\section{METHOD}

\section{Subjects \\ Sixteen undergraduate students at the State University of New York at Binghamton participated for course credit in the experiment. All sub- jects were skilled readers with English as their native language.}

\section{Apparatus}

A 60-Hz Dell noninterlaced VGA color plus monitor was used to display text, which was shown in light green on a black background. Each letter of text subtended $.33^{\circ}$ of visual angle.

Eye movements were recorded via a fifth-generation dual-Purkinje SRI eye-tracking system. The system has a visual resolution of $10 \mathrm{~min}$ of arc, and its output is linear over the vertical and horizontal range of the VGA display. Analog input from the eye tracker was digitized by an A/D converter. A separate timer was used to measure fixation durations to the nearest millisecond (see Inhoff and Briihl, 1991, for additional details).

\section{Procedure}

The subjects were tested individually. A two-dimensional calibration of the eye-tracking system began the experiment. During calibration, 
Table 1 Sample Passages

The refreshing draft was just what I needed. I enjoy a cool draft during the summertime. I enjoy a cool breeze during the summertime. I enjoy a cool beer during the summertime. Repetition condition Related 1 condition Related 2 condition I enjoy a cool soda during the summertime. Unrelated condition Note-Primary and secondary targets, which are italicized above, were not italicized in the actual study.

the subject was requested to fixate four monitor positions (left top, right top, left bottom, right bottom) as they sequentially appeared on the screen. The calibration was considered successful when the computer calculated fixation location and the actual fixation location differed by no more than one character space.

After successful calibration, the subjects read 2-line passages. Passage reading was self-paced; passage onset and offset was controlled by the subject via manual buttonpresses. After each passage reading, the subject was asked to decide whether the passage was meaningful or not. Except for a few isolated instances, all subjects performed without error in the text evaluation task.

\section{Materials}

Forty lexically ambiguous homographs constituted the set of primary targets. Ratings were used to select these primary targets. Twenty undergraduate students not participating in the reading study rated the "preferredness" of different lexical meanings of each of 70 homographs. Each of the selected 40 primary targets obtained similar preference ratings for at least two of its lexical meanings. All primary targets appeared in the first sentence/line of a two-sentence/line text passage. An attempt was made to use nonbiasing context prior to the occurrence of the primary target. The second sentence contained the secondary target, which was a repetition of the homograph, a word semantically related to one meaning of the homograph, a word semantically related to the second meaning of the homograph, or a semantically unrelated word. Primary and secondary targets occupied identical vertical text locations and were closely matched for word length. Of the 160 possible primary/secondary target pairings, $61 \%$ were of identical length, $31 \%$ differed by one character, $7 \%$ differed by two characters, and $1 \%$ differed by three characters. A sample passage is shown in Table 1 .

Forty passages containing nonhomographic words were used as filler passages. Across filler and experimental passages, half were to be rated as meaningful and half were nonmeaningful. Four lists of passages were constructed, each containing all primary targets. Across lists, each primary target was paired with a different secondary target. List assignment was counterbalanced across four successive subjects.

\section{RESULTS}

First-fixation durations and gaze durations on primary and secondary targets, as a function of their relatedness, are shown in Table 2. Although there was some variation in the first-fixation and gaze durations on primary

Table 2

First Fixation and Gaze Durations on Primary and Secondary Targets as a Function of Their Relatedness

\begin{tabular}{lcccc}
\hline & \multicolumn{4}{c}{ Relatedness Condition } \\
\cline { 2 - 5 } & Repeat & Related 1 & Related 2 & Unrelated \\
\hline \multicolumn{4}{c}{ First Fixations } \\
Primary target & 338 & 312 & 311 & 324 \\
Secondary target & 279 & 330 & 332 & 299 \\
& \multicolumn{4}{c}{ Gaze Durations } \\
Primary target & 477 & 466 & 496 & 424 \\
Secondary target & 438 & 497 & 428 & 439 \\
\hline
\end{tabular}

targets, with somewhat elevated first-fixation durations in the repetition condition and reduced gaze durations in the repetition condition, the effect of relatedness was not significant $[F(3,45)=1.53, p>.2$, and $F(3,45)=1.09$, $p>.3$, respectively].

First-fixation durations on secondary targets were, however, systematically biased by the prior reading of the primary target $[F(3,45)=8.50, p<.001]$. Using the repetition condition as baseline, first-fixation durations on the two types of related secondary targets were increased $[t(15)=3.98$ and $t(15)=6.83$, both $p s<.001]$. Using the unrelated condition as baseline, similar results were obtained with longer first-fixation durations in the two related conditions $[t(15)=2.34, p<.05$, and $t(15)=2.96, p<.01]$. However, the effect of relatedness was not significant in the gaze-duration data $[F(3,45)=1.51, p>.2]$.

\section{DISCUSSION}

The semantic relatedness between attended and unattended words did not affect the viewing time of attended words, even though unattended words were shown directly below fixated words and were thus visually quite distinct, even though readers were not actively engaged in the processing of unattended words, and even though an on-line measure was used to index semantic activation of unattended text. This finding supports the view that readers obtain little, if any, semantic information from unattended lines of text.

Semantic relatedness did, however, affect first-fixation durations on secondary targets, that is, after the primary target had been attended. The absence of a relatedness effect in the corresponding gaze data was unexpected. Compared with other experiments using two-line displays (e.g., Balota, Pollatsek, \& Rayner, 1985), the gaze durations in the current study appeared relatively long. The passage classification task may have affected refixation durations and refixation frequency on target words, adding variability to the gaze data. This could have reduced their diagnostic value in the current study.

\section{REFERENCES}

Balota, D. A., Pollatsek, A., \& Rayner, K. (1985). The interaction of contextual constraints and parafoveal visual information in reading. Cognitive Psychology, 17, 364-390.

Cowan, N. (1988). Evolving conceptions of memory storage, selective attention, and their mutual constraints within the human information-processing system. Psychological Bulletin, 104, 163-191.

Holender, D. (1986). Semantic activation without conscious identification in dichotic listening, parafoveal vision, and visual masking: A survey and appraisal. Behavioral \& Brain Sciences, 9, 1-23.

INHOFF, A. W., \& BRIHL, D. (1991). Semantic processing of unattended text during selective reading: How the eyes see it. Perception \& Psychophysics, 49, 289-294.

MARCEL, A. J. (1983). Conscious and unconscious perception: Experiments on visual masking and word recognition. Cognitive Psychology, 15, 197-237.

McConkIE, G. W. (1979). On the role and control of eye movements in reading. In P. A. Kolers, M. E. Wrolstad, \& H. Bouma (Eds.), Processing visible language (Vol. 1, pp. 37-48). New York: Plenum.

Morrison, R. E. (1984). Manipulation of stimulus onset delay in reading: Evidence for parallel programming of saccades. Journal of $E x$ perimental Psychology: Human Perception \& Performance, 5, 667-682.

Willows, D. M., \& MacKINnon, G. E. (1973). Selective reading: Attention to the "unattended" lines. Canadian Journal of Experimental Psychology, 27, 292-304.

(Manuscript received March 16, 1992.) 